CANTUA. 2017; 16:26-43

Fecha de recepción: 24.03.2017

Fecha de aceptación: 23.10.2017

\title{
Propagación in-vitro de cuatro especies de orquídeas nativas de la región Cusco
}

\section{In-vitro propagation of four species of native orchids of the Cusco region}

\author{
Máximo. A Chacón - Campana ${ }^{1}$, Luz. M Ponce- Aranibar ${ }^{1}$, Silvia. B Muñiz-Luna ${ }^{1}$, Doris. \\ P Huaracha- Quispe ${ }^{1}$, Karina Flores- Huisa ${ }^{1}$.
}

\author{
${ }^{1}$ Escuela Profesional de Biología. Facultad de Ciencias. Universidad Nacional De San Antonio \\ Abad del Cusco. Cusco, Perú
}

\section{RESUMEN}

El cultivo in vitro es una herramienta alternativa para la propagación de especies vegetales en forma masiva. En el presente trabajo se evaluó la germinación asimbiotica de las especies Epidendrum secundum, Rodriguezia longifolia, Bletia catenulata y Epidendrum spilatum en medio de cultivo Murashige y Skoog (M.S.) con tres suplementos orgánicos: agua de coco, pulpa de piña y pulpa de plátano. Las semillas provienen del Distrito de Pillcopata, Provincia de Paucartambo, Región Cusco. Se determinó el tiempo de germinación y su respuesta a tres medios de cultivo con los suplementos orgánicos, comparando con el medio testigo. Se estableció de manera artificial la división de la germinación en cinco etapas diferenciadas: imbibición, cambio de coloración por la transformación de protoplastidios en cloroplastos, inicio de la división celular, formación del protocormo y diferenciación de los órganos vegetativos. Este estudio demostró que el medio M.S suplementado con piña tiene una mejor respuesta a la germinación asimbiótica en las orquídeas Rodriguezia longifolia, Bletia catenulata y Epidendrum spilatum, mientras que para Epidendrum secundum el medio M.S. suplementado con plátano tiene la mejor respuesta a la germinación, de efecto menor es el medio suplementado con coco. El tiempo de germinación para Epidendrum secundum fue de 5 semanas, Bletia catenulata 8 semanas, Epidendrum spilatum 11 semanas y Rodriguezia longifolia 12 semanas. Se obtuvo un efecto positivo sobre la germinación de las semillas en medios con suplementos orgánicos.

PALABRAS CLAVE: cultivo in vitro, orquídeas, suplementos orgánicos. 


\begin{abstract}
ABSTRAC
In vitro culture is an alternative tool for the mass propagation of plant species. In the present work, the asymbiotic germination of the Epidendrum secundum, Rodriguezia longifolia, Bletia catenulata and Epidendrum spilatum species was evaluated in Murashige and Skoog (M.S.) culture medium with three organic supplements: coconut water, pineapple pulp and banana pulp. The seeds come from the Pillcopata District, Paucartambo Province, Cusco Region. Germination time and its response to three culture media with organic supplements were determined, comparing with the control medium. The germination division was artificially established in five differentiated stages: imbibition, color change due to the transformation of protoplastids into chloroplasts, initiation of cell division, formation of the protoform and differentiation of vegetative organs. This study showed that the medium S.M supplemented with pineapple has a better response to asymbiotic germination in Rodriguezia longifolia, Bletia catenulata and Epidendrum spilatum orchids, while for Epidendrum secundum the M.S. supplemented with banana has the best response to germination, of less effect is the medium supplemented with coconut. Germination time for Epidendrum secundum was 5 weeks, Bletia catenulata 8 weeks, Epidendrum spilatum 11 weeks and Rodriguezia longifolia 12 weeks. A positive effect was obtained on the germination of the seeds in media with organic supplements
\end{abstract}

KEYWORDS: In vitro culture, orchids, organic supplements.

\title{
INTRODUCCIÓN
}

La germinación de las semillas de orquídeas es un proceso diferente al de otras plantas, debido a que los embriones son inmaduros y no presentan tejidos nutricionales, por lo que requieren la asociación con hongos, que actúan como nodrizas que les proporcionan los nutrimentos necesarios (Ardiiti, J y Ernest, R. 1993).

Las semillas germinan formando un protocormo, el que puede o no producir inmediatamente clorofila. El protocormo sobrevive gracias a que el hongo proporciona azúcares y el protocormo le provee ciertas vitaminas y un hábitat donde desarrollar (Arditti, J. 1992)

El medio de cultivo Murashige y Skoog (1962), se ha probado para la germinación y crecimiento de muchas especies, obteniéndose resultados óptimos debido a su contenido en sales inorgánicas, carbohidratos, vitaminas y aminoácidos, que brinda un elevado contenido de nitrógeno y potasio necesario para su nutrición. A través del tiempo se ha mejorado la germinación en orquídeas, utilizando medios de cultivos básicos suplementados con componentes orgánicos. 
En el presente estudio se evalúa la germinación asimbiótica de las especies de orquídeas nativas de la Región Cusco: Epidendrum secundum, Rodriguezia longifolia, Bletia catenulata y Epidendrum spilatum en medios de cultivo Murashige y Skoog (MS) con suplementos orgánicos con agua de coco, jugo de piña y plátano verde (Figuras 1, 2, 3 y 4). Demostrar que la adición de suplementos orgánicos aumenta el proceso de germinación de las semillas de las orquídeas y al mismo tiempo reducir los costos.

También se pretende establecer las etapas y tiempo de germinación en las cuatro especies de estudio.
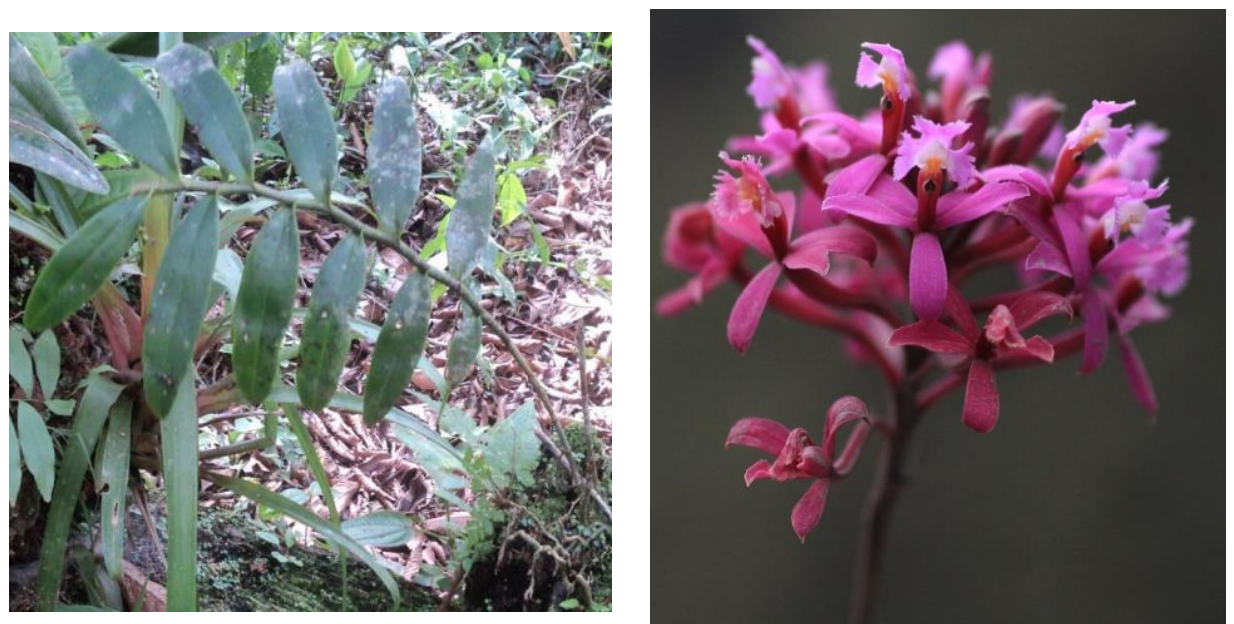

Figura 1. Epidendrum secundum. (Fotografía Manuel Llanos).
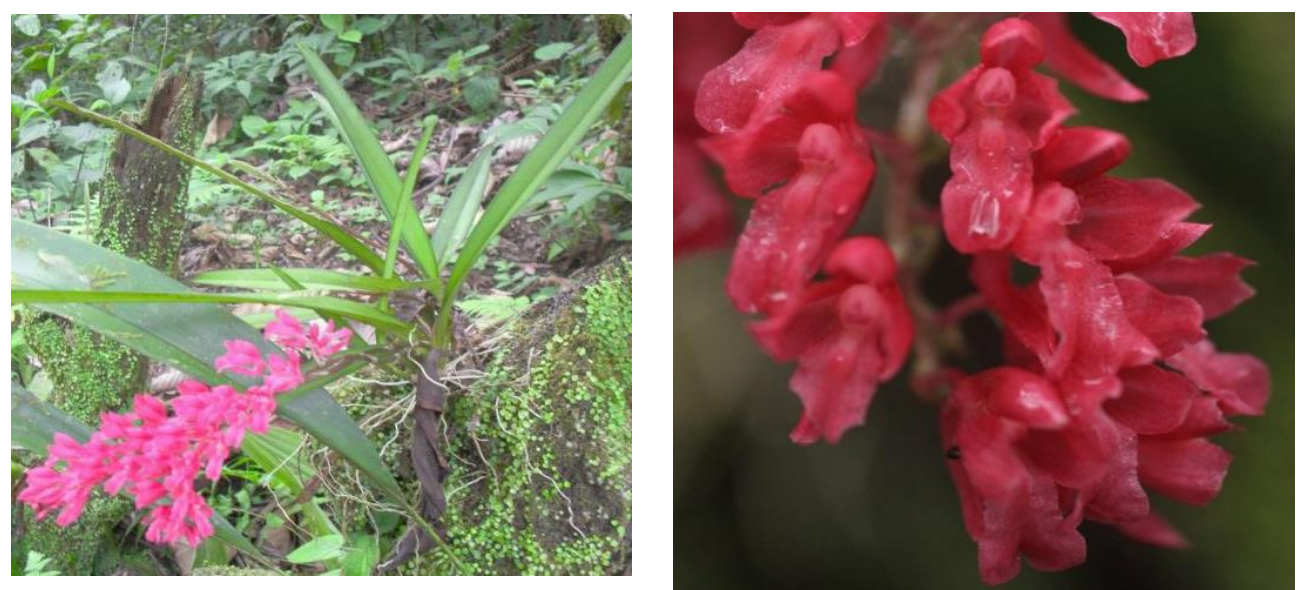

Figura 2. Rodriguezia longifolia. (Fuente: Fotografía Manuel Llanos). 

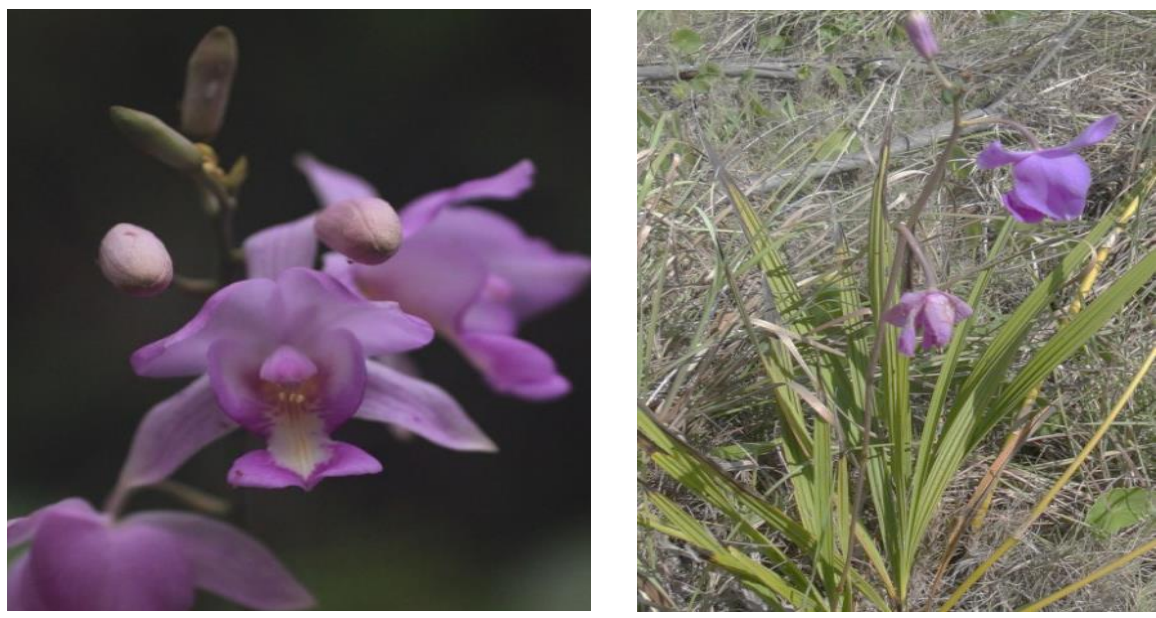

Figura 3. Bletia catenulata. (Fotografía Manuel Llanos).
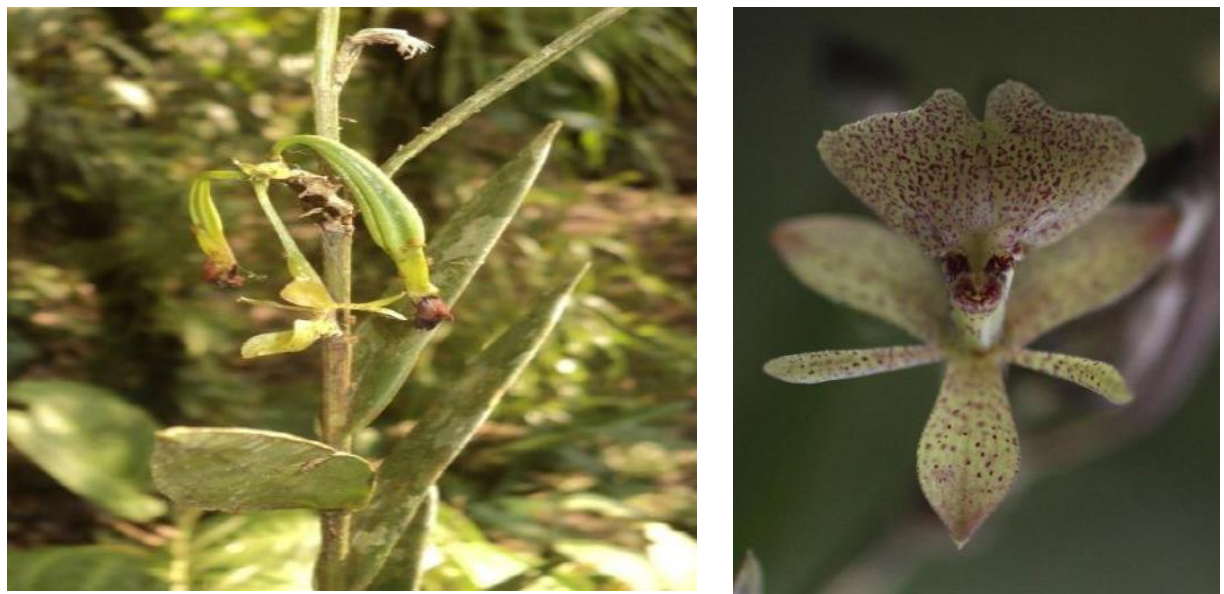

Figura 4. Epidendrum spilatum. (Fotografía Manuel Llanos).

\section{METODOLOGÍA}

Colecta de las muestras:

Se colectaron capsulas cerradas de una coloración verde claro maduras sin ningún daño físico, para determinar su madurez, también se colectaron capsulas maduras parcialmente abiertas

\section{Medios de cultivo:}

\section{A.- Solución madre de macronutrientes, micronutrientes y vitaminas:}

Se utilizó la fórmula propuesta por Murashige y Skoog (1962).

Se preparó un stock de las sales MS (macronutrientes, micronutrientes y vitaminas).

B.- Medios de cultivo. - Para el estudio se utilizaron cuatro medios de cultivo que son: 
- MB: Medio de Cultivo Murashige y Skoog que contiene los nutrientes minerales, vitaminas y sacarosa.

- MC: Medio de Cultivo Murashige y Skoog suplementado con 500ml/l de agua de coco.

- MPi: Medio de Cultivo Murashige y Skoog suplementado con $200 \mathrm{gr} / \mathrm{l}$ de pulpa de piña.

- MP: Medio de Cultivo Murashige y Skoog suplementado con: $100 \mathrm{gr} / \mathrm{l}$ de plátano verde.

Estabilizado a un pH de 5.5 que es el ideal para el cultivo in vitro de orquídeas.

Gómez et,al. (2006)

\section{Preparación/Desinfección Del Explante.}

a) Protocolo de desinfección para capsulas cerradas:

Introducir la cápsula por 10 minutos aproximadamente en una solución de hipoclorito de sodio al 5\%, enjuagar con agua destilada, sumergimos en alcohol al $70 \%$ y flamear (figura 5 ).
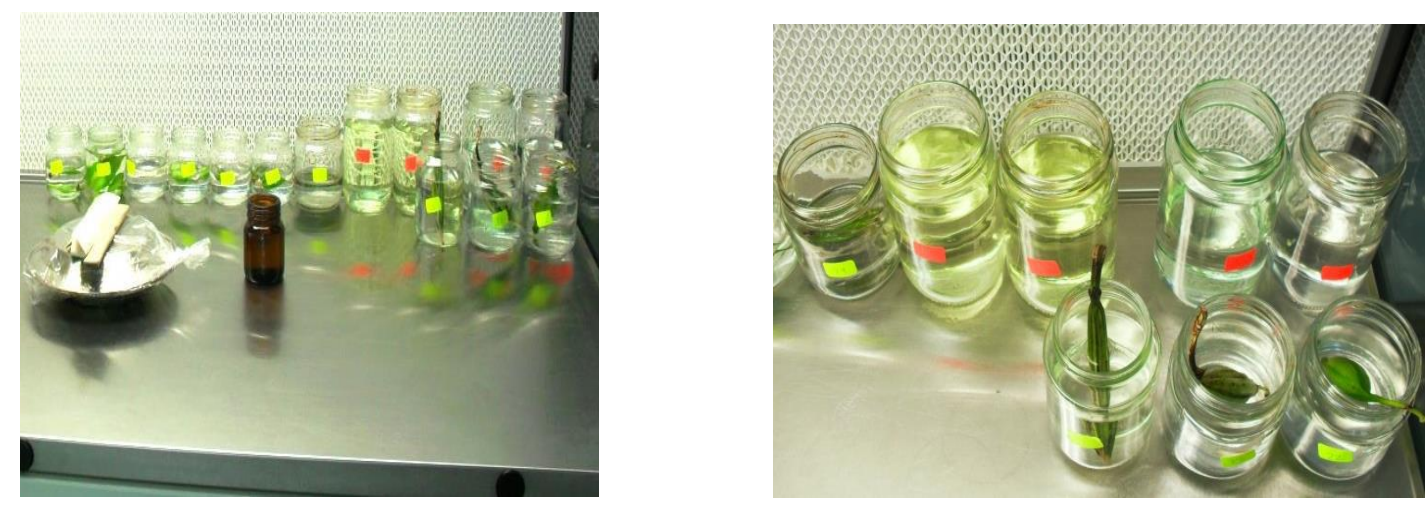

Figura 5. Protocolo de desinfección de capsulas cerradas.

\section{b) Protocolo de desinfección para capsulas abiertas:}

Una cantidad de semillas se colocan en papel tissu y empaquetar, se colocan en frascos y se añade una solución de hipoclorito de sodio al $5 \%$, Se enjuaga con agua destilada por 1 minuto (figura 6). Para luego proceder a sembrar, los frascos de siembra se colocan en un lugar de incubación a 18 horas de iluminación por 6 horas de oscuridad. La evaluación de germinación 
se realizó semanalmente, mediante observaciones directas y al microscopio estereoscópico durante 13 semanas en los 4 medios de cultivos.
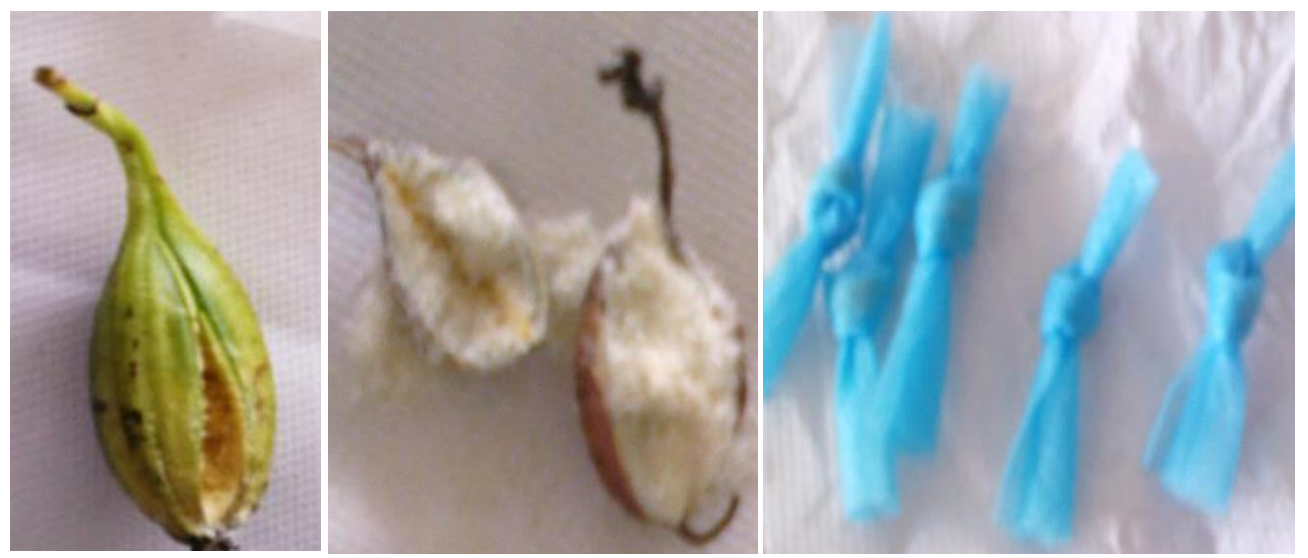

Figura 6. Protocolo de desinfección de capsulas abiertas.

\section{RESULTADOS}

\section{Etapas de germinación de la semilla.}

Durante el tiempo de evaluación se observaron los cambios que presentan las semillas, las que se clasificaron artificialmente en cinco etapas para las especies en estudio (tabla 1):

I: Imbibición, que comprende la absorción de agua por las semillas, las que comienzan a tener un leve incremento de volumen.

II: Semillas verdes, esta segunda etapa se diferencia por el cambio de coloración que adquieren las semillas, por la transformación de los protoplastidios a cloroplastos.

III: Inicio de división celular, se caracteriza por la división mitótica de las células seminales dando un mayor incremento en volumen a las semillas,

IV: Protocormo, caracterizado por ser un embrión poco diferenciado con un crecimiento característico.

V: Desarrollo de órganos axiales, aparición de brote y raíces. 
Tabla 1.

Evaluación de las etapas de germinación in vitro de semillas de las 4 especies de orquídeas en semanas.

\begin{tabular}{|c|c|c|c|c|c|c|c|c|c|c|c|c|c|c|c|c|}
\hline \multirow{2}{*}{$\stackrel{N^{\circ}}{\text { SEMANAS }}$} & \multicolumn{4}{|c|}{$\begin{array}{l}\text { Epidendrum } \\
\text { secundum }\end{array}$} & \multicolumn{4}{|c|}{$\begin{array}{c}\text { Rodriguezia } \\
\text { longifolia }\end{array}$} & \multicolumn{4}{|c|}{ Bletia catenulata } & \multicolumn{4}{|c|}{$\begin{array}{l}\text { Epidendrum } \\
\text { spilatum }\end{array}$} \\
\hline & MB & MC & $M P i$ & MP & $\mathrm{MB}$ & MC & $M P i$ & MIP & $\mathrm{MB}$ & MC & MPi & MP & $\mathrm{MB}$ & MC & $M P i$ & MP \\
\hline 1 & 1 & 1 & 1 & 1 & 1 & 1 & 1 & 1 & 1 & 1 & 1 & 1 & 1 & 1 & 1 & 1 \\
\hline 2 & 1 & 1 & 11 & 11 & 1 & 1 & 1 & 1 & 1 & 1 & 1 & 1 & 1 & 1 & 1 & 1 \\
\hline 3 & 11 & 11 & II & III & 1 & 1 & 1 & 1 & 1 & 1 & 11 & 11 & 1 & 1 & 1 & 1 \\
\hline 4 & 11 & 11 & III & IV & 1 & 1 & 1 & 1 & II & 1 & 11 & 11 & 1 & 1 & II & 1 \\
\hline 5 & 11 & 11 & IV & IV & 1 & 11 & 1 & 1 & 11 & 1 & 11 & 11 & 1 & 1 & 11 & 1 \\
\hline 6 & 11 & 11 & IV & V & 11 & 11 & 11 & 11 & 11 & 1 & III & 11 & 1 & 11 & 11 & 11 \\
\hline 7 & III & III & V & V & 11 & 11 & 11 & 11 & 11 & 1 & IV & 111 & II & II & 11 & 11 \\
\hline 8 & III & IV & V & $\mathrm{V}$ & II & 11 & 11 & 11 & 11 & 1 & IV & IV & II & 11 & 11 & 11 \\
\hline 9 & IV & IV & V & V & II & 11 & 11 & 11 & III & II & $\mathrm{V}$ & IV & II & 11 & 11 & 11 \\
\hline 10 & IV & V & V & V & 11 & 11 & III & 11 & IV & 11 & $V$ & IV & II & 11 & III & 11 \\
\hline 11 & $V$ & V & V & V & II & 11 & IV & 11 & IV & 11 & V & V & 11 & III & IV & 11 \\
\hline 12 & $V$ & V & V & V & 11 & 111 & IV & 11 & V & 11 & V & V & 11 & IV & $V$ & III \\
\hline 13 & $V$ & V & $V$ & V & III & IV & IV & 111 & V & 11 & V & V & III & V & $\mathrm{V}$ & IV \\
\hline
\end{tabular}

Leyenda.

Medios. MB (Murashige y Skoog-MS), MC (MS agua de coco), MPi (MS pulpa de piña), MP (MS pulpa de plátano verde)

\section{Epidendrum secundum}

Las semillas de Epidendrum secundum, son de forma alargada, con los extremos aguzados y ensanchado en la parte media, con la superficie lisa; la semilla está formada por una masa irregular de células, rodeadas por una testa (figura 7). 

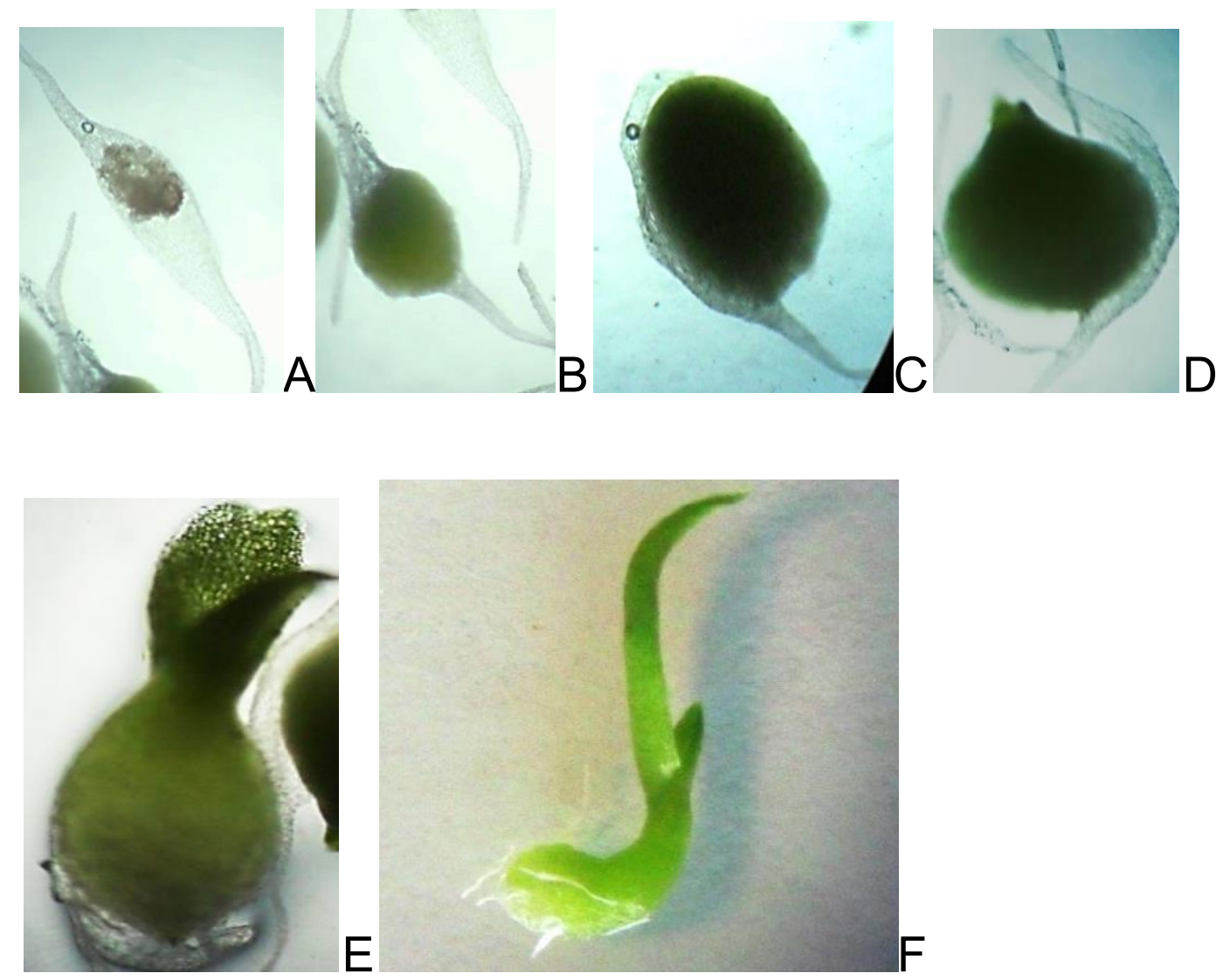

Figura 7. Etapas de germinación in vitro de Epidendrum secundum. A: Imbibición. B: Semilla verde. C: Inicio de división celular. D: Protocormo. E, F: Desarrollo de hojas y raíces a un aumento de 100x.

El medio de cultivo de Murashige y Skoog suplementado con plátano resulta ser el mejor para la inducción a germinación para Epidendrum secundum, manteniendo fases cortas, con una diferenciación de los órganos axiales diferenciadas a partir de la quinta semana, seguida en eficiencia por el medio enriquecido con jugo de piña, las que presentan una diferenciación de hojas y raíces a partir de la sexta semana, mientras que los medios Murashige y Skoog, y M. S. enriquecido con agua de coco son los menos eficientes con formación de órganos a partir de la décima y novena semana respectivamente (tabla 2 y figura 8). 
Tabla 2.

Tiempo de duración de las etapas de germinación, en semanas de Epidendrum secundum.

\begin{tabular}{lllll}
\hline ETAPA/SEMANA & MB & MC & MPI & MP \\
\hline Inbibición & $0-2$ & $0-2$ & $0-1$ & $0-1$ \\
Semilla verde & $2-6$ & $2-6$ & $1-3$ & $1-2$ \\
Inicio de Div. & $6-8$ & $6-7$ & $3-4$ & $2-3$ \\
Celular & & & & \\
Protocormo & $8-10$ & $7-9$ & $4-6$ & $3-5$ \\
Desarrollo & 10 & 9 & 6 & 5 \\
\hline
\end{tabular}

Leyenda.

Medios: MB (Murashige y Skoog-MS), MC (MS agua de coco), MPi (MS pulpa de piña), MP (MS pulpa de plátano verde).

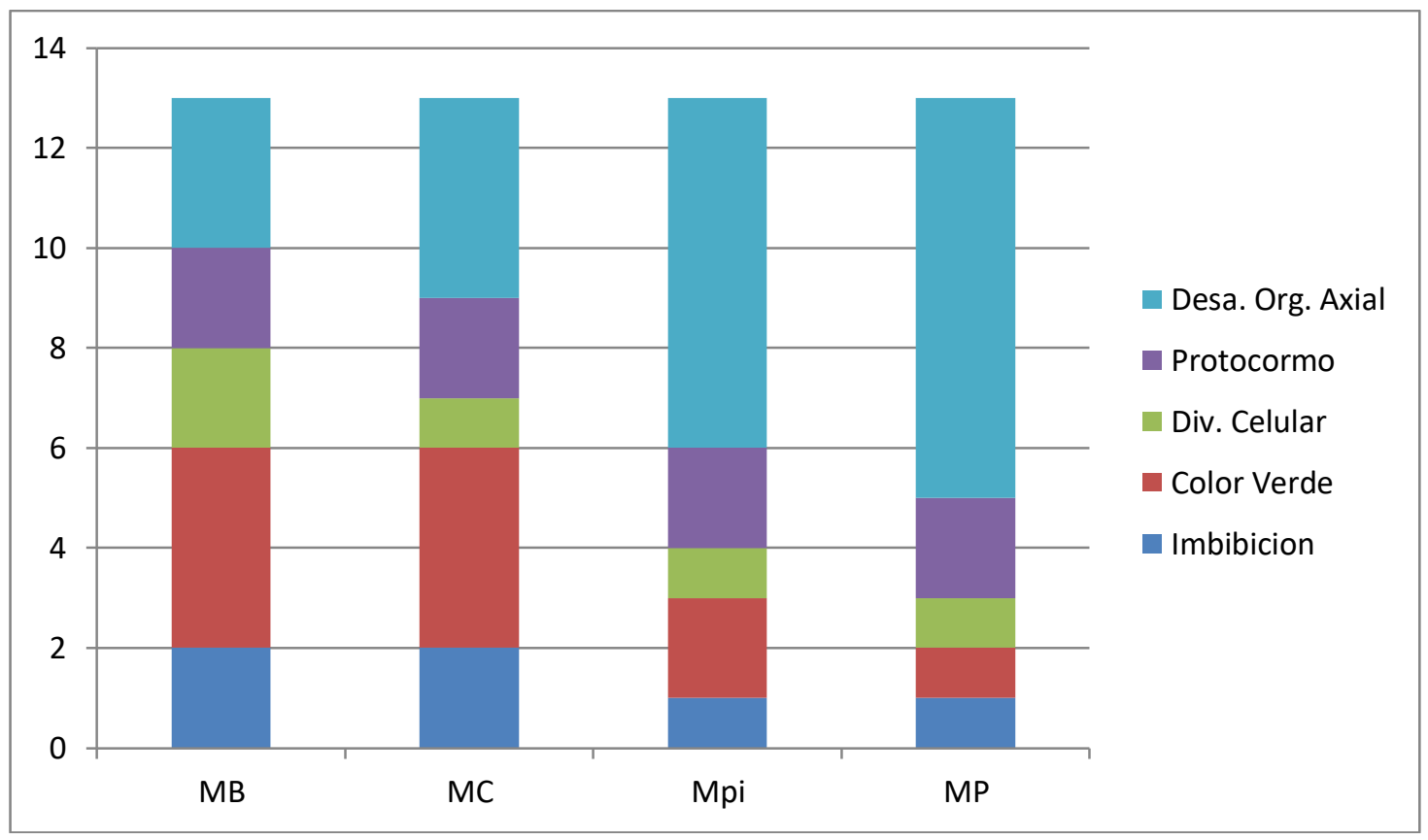

Figura 8. Etapas de germinación in vitro de Epidendrum secundum.

\section{Rodriguezia longifolia}

Las semillas de Rodriguezia longifolia son de tamaño pequeño, de superficie lisa y forma lenticelar corta, formada por una masa celular globosa (figura 9). En el desarrollo de las semillas, las etapas de mayor duración fueron la de imbibición y semilla verde en todos los medios de cultivo. 

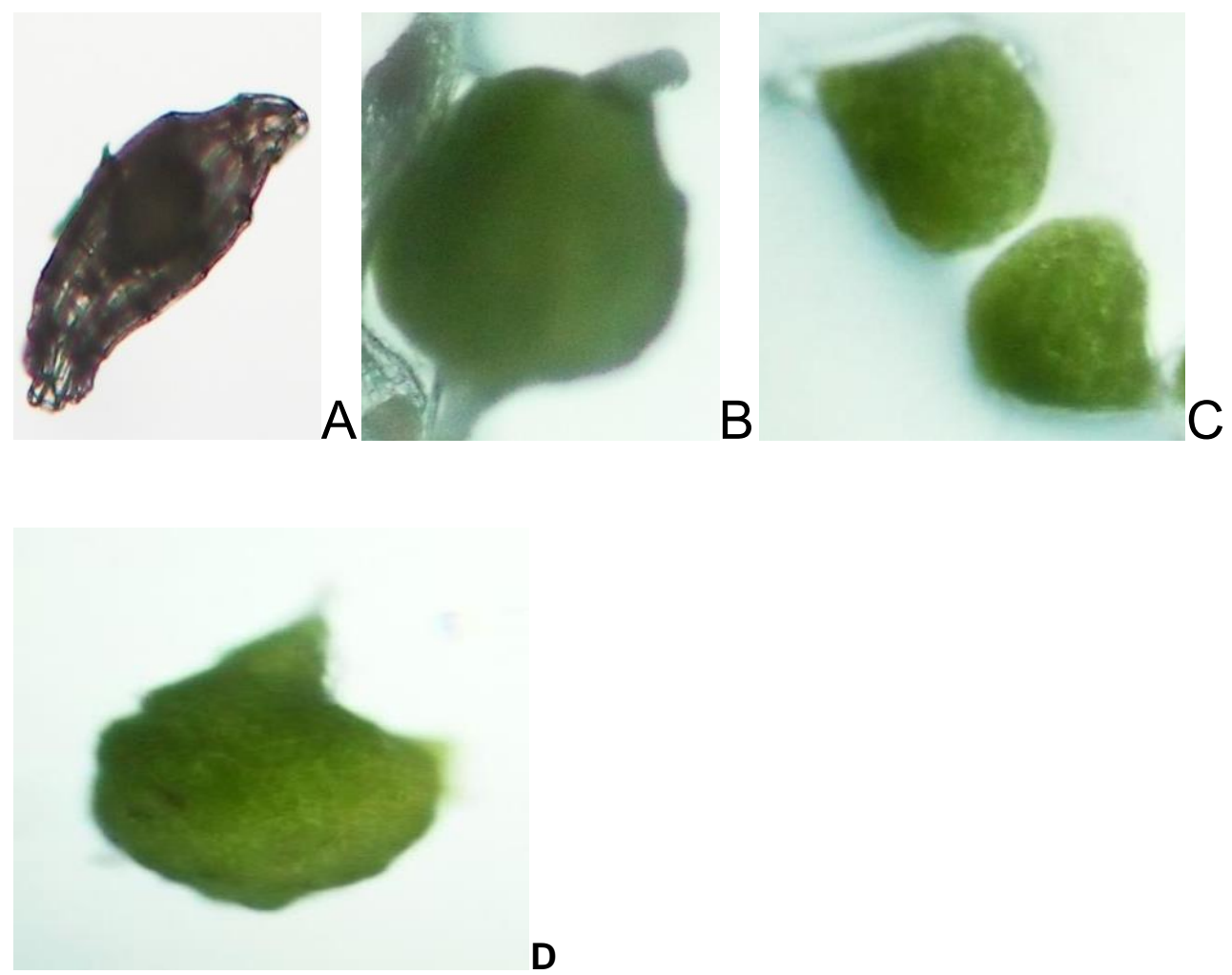

Figura 9. Etapas de germinación in vitro de Rodriguezia longifolia. A: Imbibición. B: Semilla verde. C: División Celular. D: Protocormo.

En la germinación de Rodriguezia longifolia las etapas de imbibición y la del cambio de coloración son prolongadas, de 9 a 12 semanas. El medio de cultivo que estimulo mejor la germinación hasta la etapa de formación de órganos axiales es el medio M.S. suplementado con jugo de piña, observándose la diferenciación de hojas a la semana 12.En el medio de M. S. suplementado con agua de coco se llegó hasta la etapa de formación de protocormo, en cambio en los medio de M.S. y M.S. suplementado con plátano el comportamiento fue similar, con una duración por etapas similar, sin llegar a formar protocormo ni órganos, dentro de las 13 semanas de observación (tabla 3 y figura 10). 
Tabla 3.

Tiempo de las etapas de desarrollo in vitro de Rodriguezia longifolia

\begin{tabular}{lllll}
\hline ETAPASEMANA & MB & MC & MPI & MP \\
\hline Imbibición & $0-5$ & $0-4$ & $0-5$ & $0-5$ \\
Semilla verde & $5-12$ & $4-11$ & $5-9$ & $5-12$ \\
Inicio de Div. & $12-13$ & $11-12$ & $9-10$ & $12-13$ \\
Celular & & & & \\
Protocormo & -- & $12-13$ & $10-12$ & -- \\
\hline Desarrollo & -- & -- & $12-13$ & -- \\
\hline
\end{tabular}

Leyenda.

Medios: MB (Murashige y Skoog-MS), MC (MS agua de coco), MPi (MS pulpa de piña), MP (MS pulpa de plátano verde).

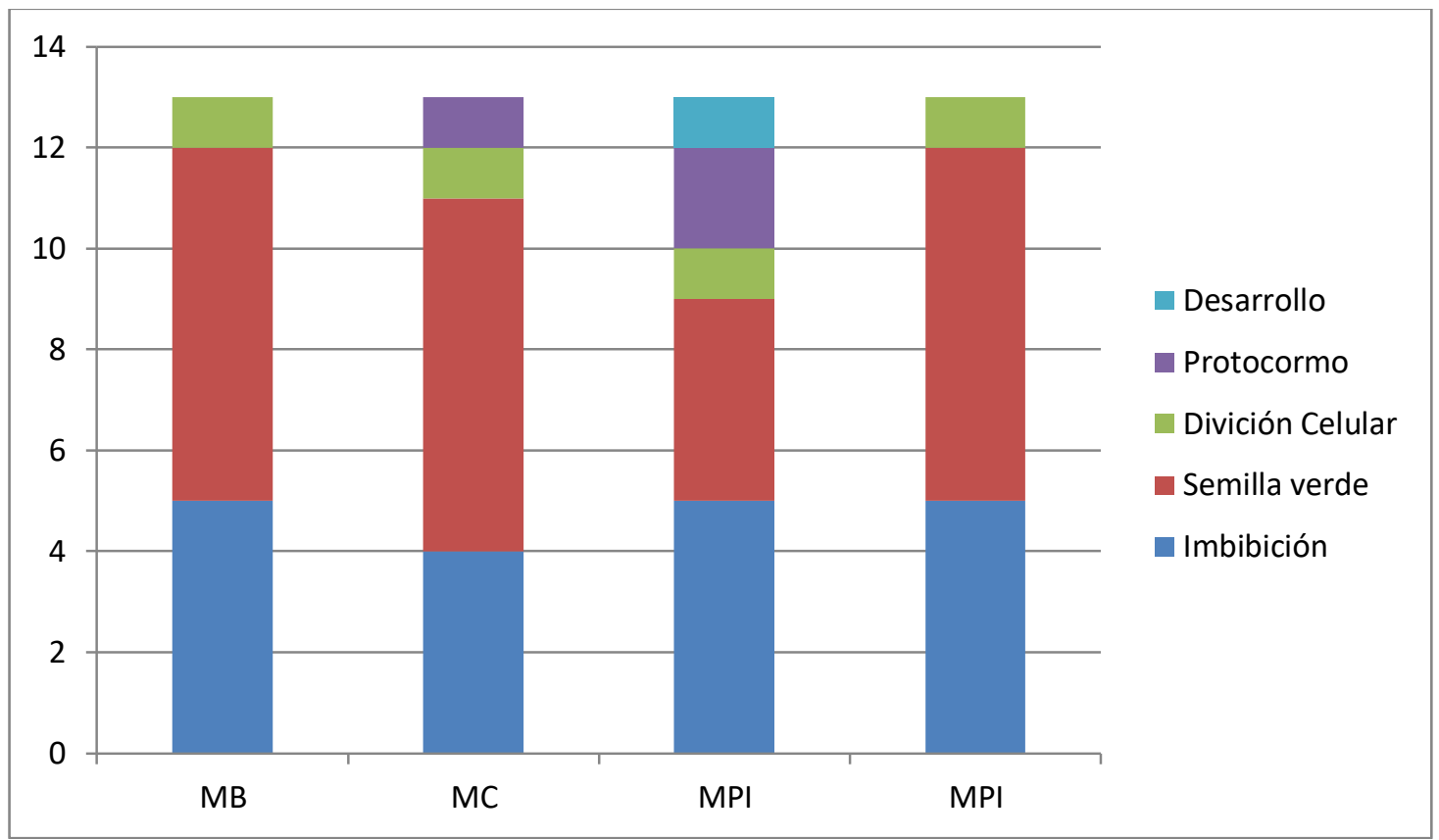

Figura 10. Etapas de desarrollo in vitro de Rodriguezia longifolia

\section{Bletia catenulata}

Las semillas de Bletia catenulata son relativamente más alargadas en comparación con las otras semillas en estudio, presentan una superficie irregular, cubierta por pelos cortos y engrosados, son alargados, en los que la envoltura seminal es más desarrollada, ahusada, levemente ensanchada al medio y con los extremos adelgazados, estos extremos mayormente son encorvados, con apariencia desecada (figura 11). La semilla está conformada por escasas células, dispuestas en una masa irregular. 

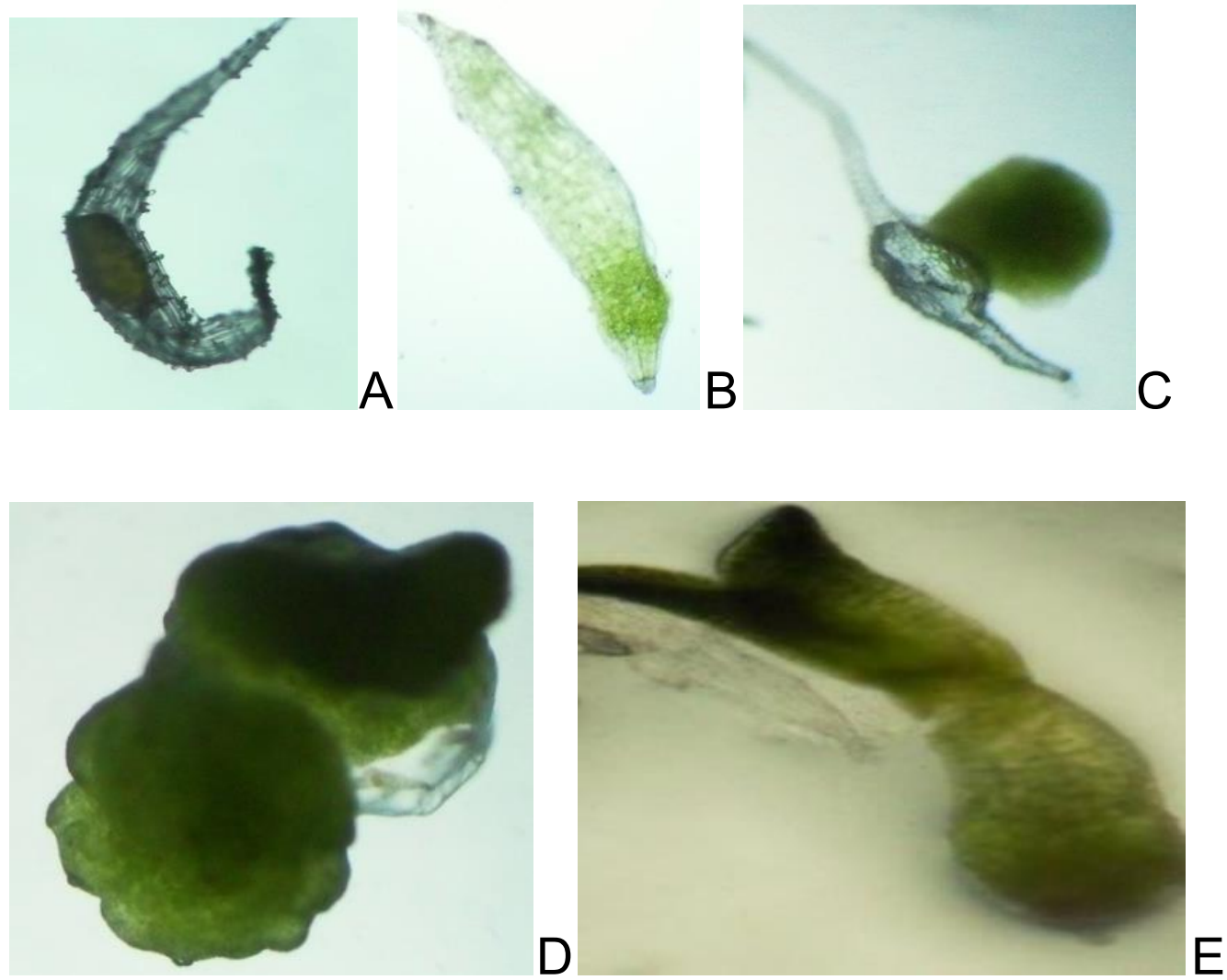

Figura 11. Etapas de desarrollo in vitro de Bletia catenulata. A: Imbibición. B: Semilla verde. C: EN división celular. D: Protocormo. E: Desarrollo de hojas.

En el proceso de germinación para Bletia catenulata se tiene que el medio de cultivo de M.S. con el suplemento de jugo de piña es el que brindo mejores condiciones para una rápido y mejor germinación, mostrando el desarrollo de las hojas a la octava semana, con etapas cortas; seguido del medio de M.S. suplementado con plátano con el desarrollo de las hojas a la décima semana. El medio de M.S. muestra un desarrollo continuo, pero lento con los dos medios anteriores. El medio de cultivo d M.S. suplementado con agua de coco alargó las etapas de imbibición y de semillas verdes, sin completase la formación del protocormo y menos las formaciones de órganos vegetativos. Un aspecto particular es el hecho que durante el inicio de la división celular la semilla en su desarrollo se libera de sus envolturas, quedando libre en el medio (tabla 4 y figura 12). 
Tabla 4: Tiempo de las etapas de germinación in vitro de Bletia catenulata

\begin{tabular}{lllll}
\hline ETAPA/SEMANA & MB & MC & MPI & MP \\
\hline Imbibición & $0-3$ & $0-8$ & $0-2$ & $0-2$ \\
Semilla verde & $3-8$ & $8-13$ & $2-5$ & $2-6$ \\
Inicio de Div. & $8-9$ & -- & $5-6$ & $6-7$ \\
Celular & & & & \\
Protocormo & $9-11$ & -- & $6-8$ & $7-10$ \\
Desarrollo & $11-13$ & -- & $8-13$ & $10-13$ \\
\hline
\end{tabular}

\section{Leyenda.}

Medios: MB (Murashige y Skoog-MS), MC (MS agua de coco), MPi (MS pulpa de piña), MP (MS pulpa de plátano verde.

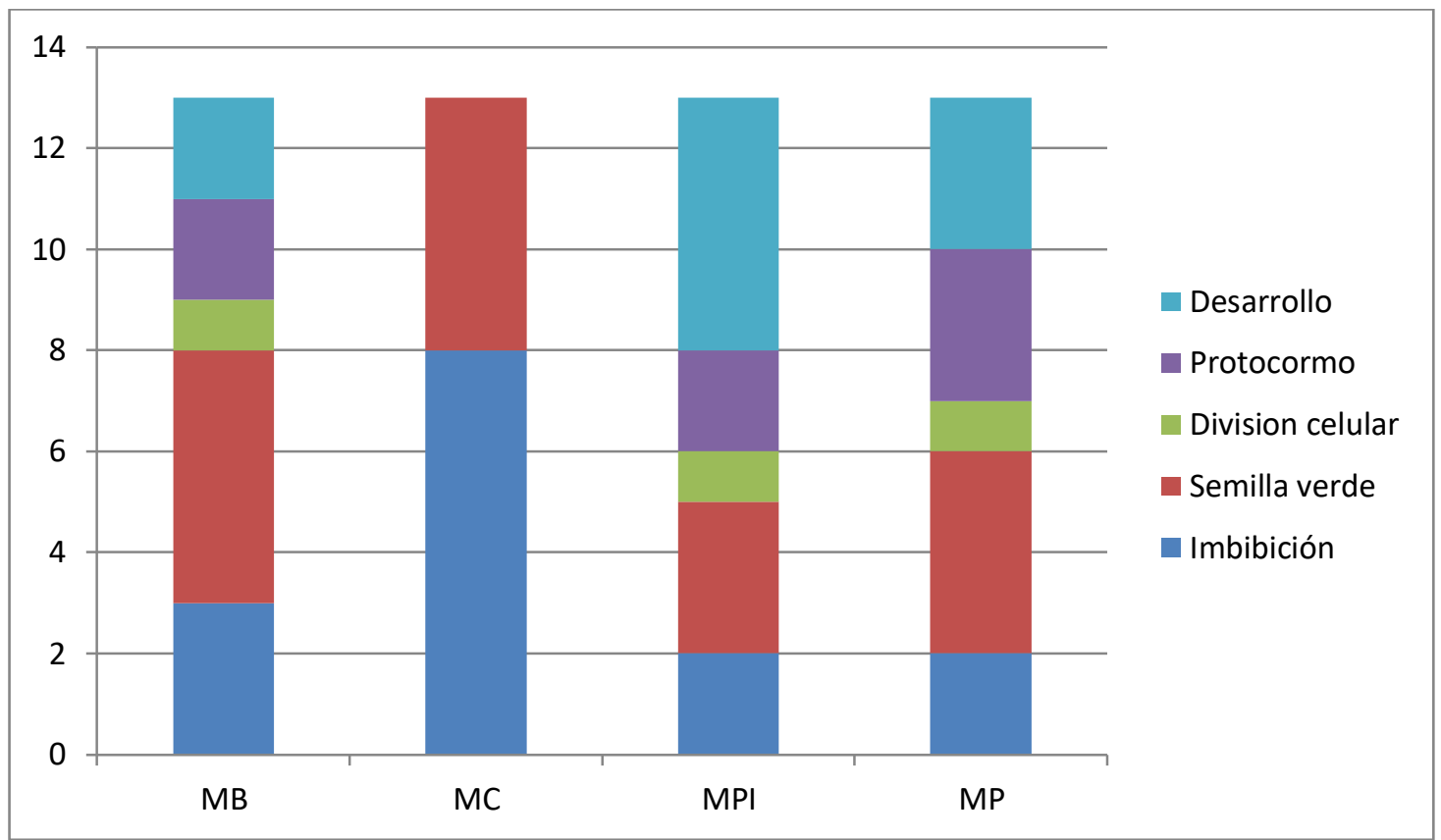

Figura 12. Tiempo de las etapas de germinación in vitro de Bletia catenulata.

\section{Epidendrum spilatum}

Las semillas de Epidendrum spilatum son las más pequeñas dentro de las especies de trabajo, la envoltura que protege a la semilla es lisa y se dispone a manera de un capuchón, cerrado hacia uno de sus extremos y abierto de manera abarquillada en el otro, con la semilla depositada dentro del capuchón, la semilla es compacta y bastante pequeña, de forma globosa e indiferenciada (figura 13). En el proceso de germinación se libera rápidamente de sus envolturas puesto que una parte de ellas está expuesta. 

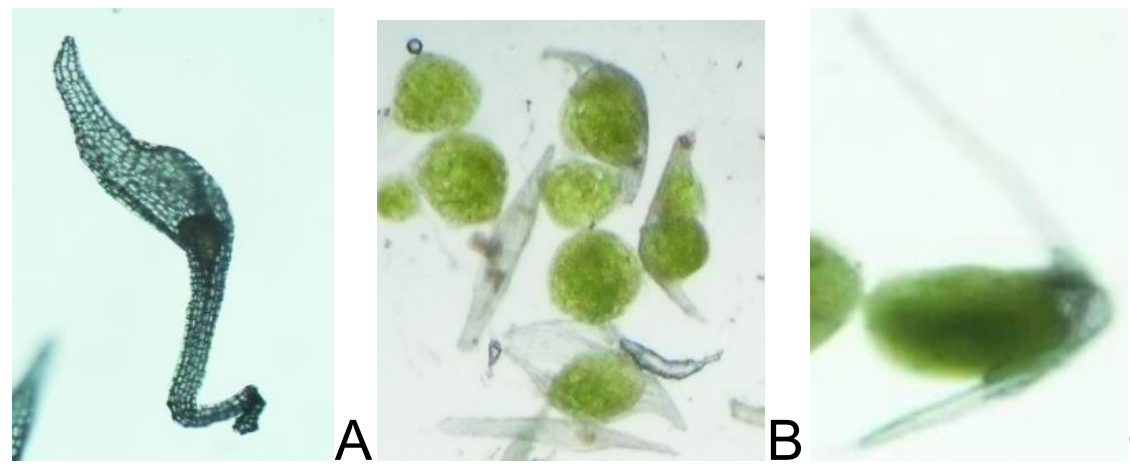

A

B

C
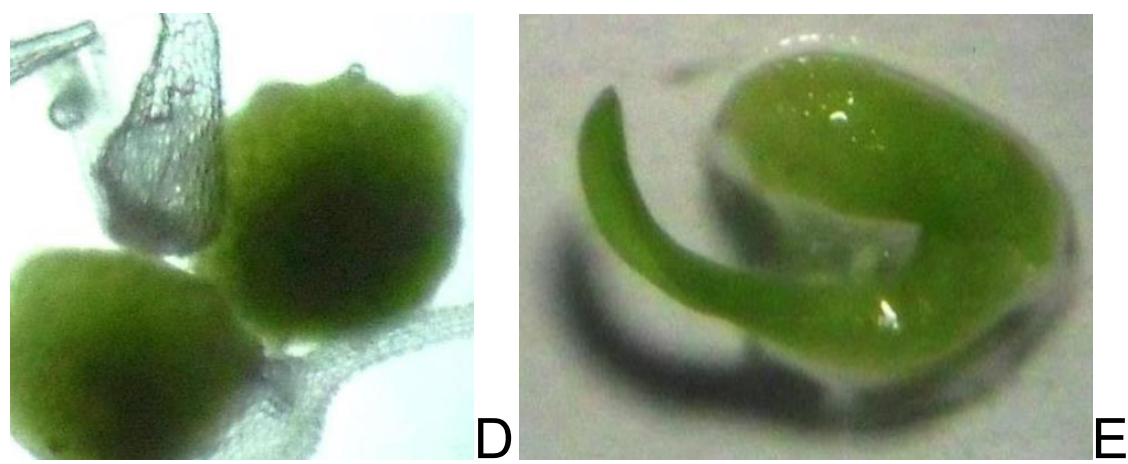

Figura 13. Etapas de germinación in vitro de Epidendrum spilatum. A: Imbibición. B: Semilla verde. C: Germinación. D: Protocormo. E: Desarrollo de hojas.

Para Epidendrum spilatum las etapas más prolongadas son la de imbibición y la de adquirir la coloración verde, las que tuvieron una duración de 9 a 12 semanas. Los medios de cultivo en el que lograrón desarrollar estructuras foliares es en el medio M.S. suplementado con jugo de piña cuya diferenciación se apreció a la semana decimoprimera, mientras que en el medio M.S. con agua de coco alcanzo esta etapa a la decimosegunda semana. El medio M.S. suplementado con plátano a la décimo tercera semana alcanzo la formación del protocormo, el medio M.S. en las 13 semanas alcanzo realizar la división de sus células (tabla 5 y figura 14). 
Tabla 5. Tiempo de las etapas de germinación in vitro de Epidendrum spilatum

\begin{tabular}{lllll}
\hline & MB & MC & MPI & MP \\
\hline Imbibición & $0-6$ & $0-5$ & $0-3$ & $0-5$ \\
Semilla verde & $6-12$ & $5-10$ & $3-9$ & $5-11$ \\
$\begin{array}{l}\text { Inicio de Div. } \\
\text { Celular }\end{array}$ & $12-13$ & $10-11$ & $9-10$ & $11-12$ \\
Protocormo & -- & $11-12$ & $10-11$ & $12-13$ \\
Desarrollo & -- & $12-13$ & $11-13$ & -- \\
\hline
\end{tabular}

Leyenda.

Medios: MB (Murashige y Skoog-MS), MC (MS agua de coco), MPi (MS pulpa de piña), MP (MS pulpa de plátano verde.

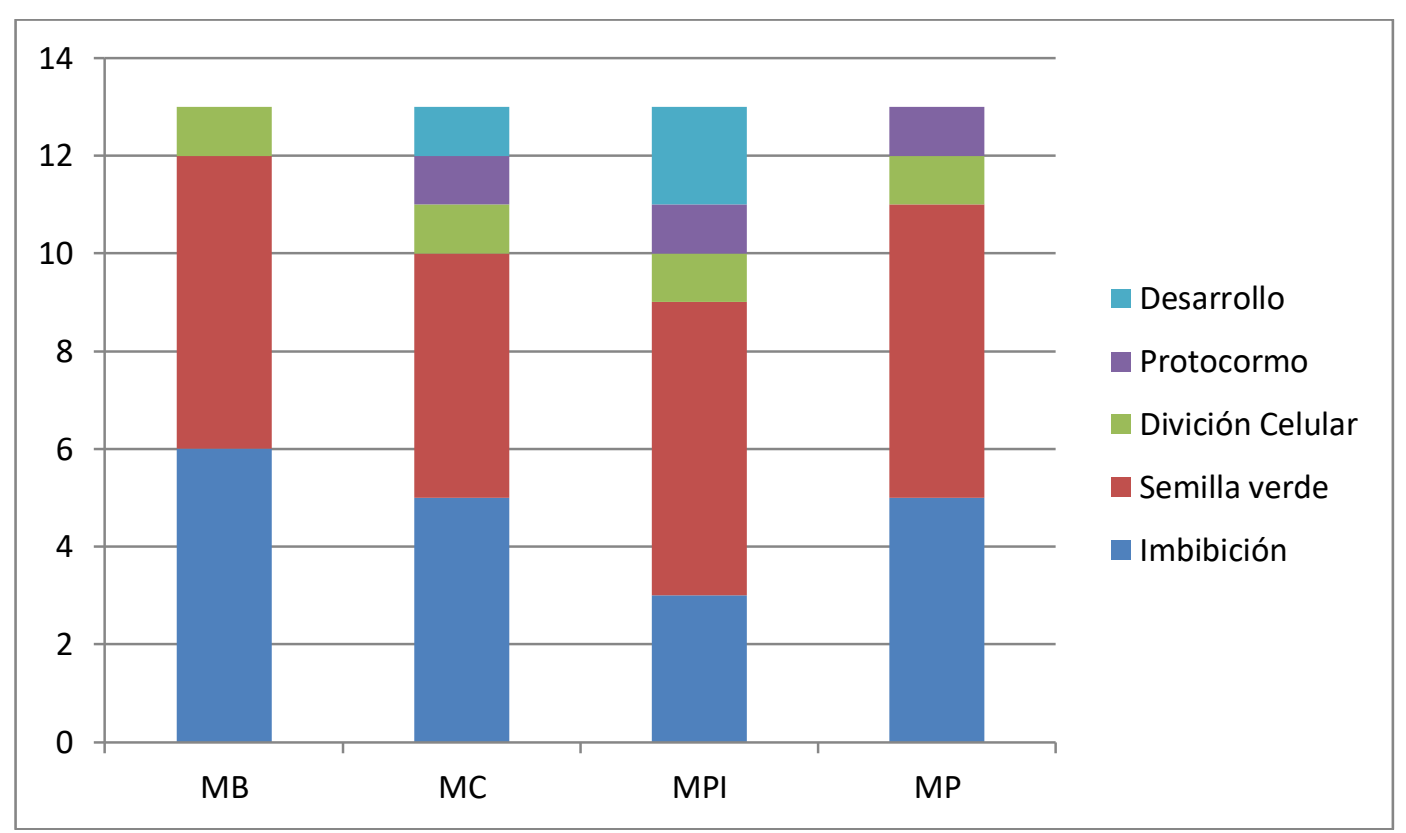

Figura 14. Tiempo de las etapas de germinación in vitro de Epidendrum spilatum.

\section{Tiempo de Germinación}

El medio de cultivo M.S. suplementado con jugo de piña (MPi) I en las especies de estudio mayor eficiencia en el proceso de la germinación, observada dentro de las 13 semanas de evaluación, siendo superado por una semana solo por el medio de M.S. suplementado con plátano, para la germinación en la especie Epidendrum secundum.

Las especies que presentan mayor tiempo en completar el proceso de germinación en los medios de cultivo evaluados son Epidendrum spilatum y 
Rodriguezia longifolia con 11 y 12 semanas respectivamente la que podría deberse al obtenerse de semillas de cápsulas frescas (tabla 6 y figura 15).

Tabla 6. Tiempo de germinación en semanas por medio de cultivo.

\begin{tabular}{|c|c|c|}
\hline Especie & $\begin{array}{l}\text { T. de germ. } \\
\text { Medio Cult. } 1\end{array}$ & $\begin{array}{l}\text { T.de germ. } \\
\text { Medio Cult. } 2\end{array}$ \\
\hline $\begin{array}{l}\text { Epidendrum } \\
\text { secundum }\end{array}$ & $5 / M P$ & 6/MPi \\
\hline Rodriguezia longifolia & 12/ MPi & -- \\
\hline Bletia catenulata & 8/ MPi & 10/MP \\
\hline Epidendrum spilatum & 11/ MPi & $12 / M C$ \\
\hline
\end{tabular}

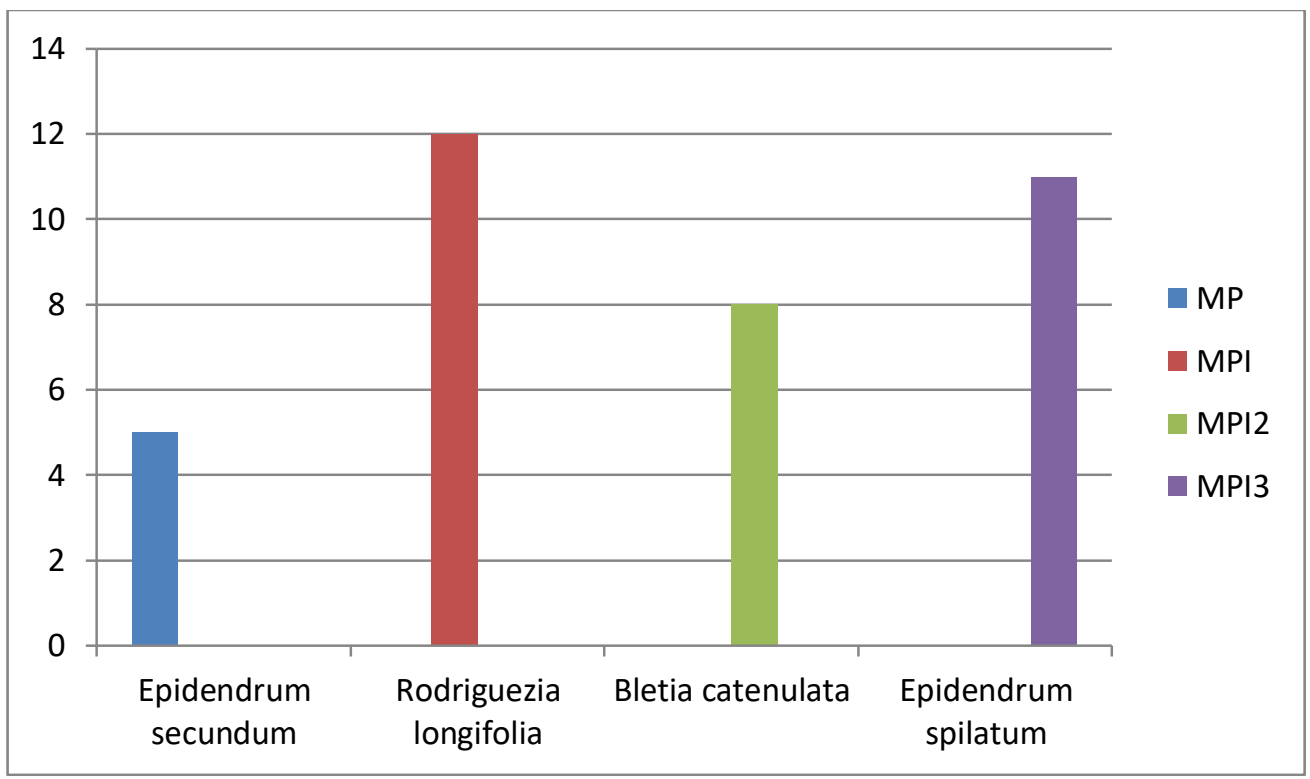

Figura 15. Tiempo de las etapas de germinación in vitro por especie.

\section{DISCUSION}

El medio MS sin suplementos orgánicos presenta para Epidendrum secundum, Rodriguezia longifolia y Epidendrum spilatum el mayor tiempo de germinación, resultado semejante es el por Sardi y Guzman (2007) que obtuvieron el menor porcentaje de germinación en el medio sin compuestos orgánicos para Epidendrum secundum. 
El medio MS suplementado con jugo de piña para Rodriguezia longifolia, Bletia catenulata y Epidendrum spilatum presento el menor tiempo de germinación, este resultado se relaciona con el trabajo presentado por Salazar y Orlando (2012) que tuvieron la mejor respuesta con el medio MS suplementado con jugo de piña a la germinación asimbiotica y formación de plántulas en las orquídeas Prosthechea vespa y Sobralia klotzscheana siendo un suplemento adecuado para propagar plantas in vitro.

El medio MS suplementado con plátano para Epidendrum secundum obtuvo el menor tiempo de germinación, relaciona con los resultados obtenidos por Sardi y Guzmán (2007) que observaron la mejor germinación con medio suplementado con plátano.

La germinación y desarrollo de plántulas de híbridos de Phalaenopsis, desarrollado por Salazar y Anaya (2013) presentaron la mejor germinación en el medio de cultivo MS suplementado con agua de coco, resultado que no coincide con el presente trabajo, posiblemente debido a que todas las especies tienen diferentes necesidades nutricionales, por tal motivo, se ve la necesidad de estudiar las condiciones para cada especie como lo afirma Roca, W. y Mroginsky, L. (1991).

\section{CONCLUSIONES}

El medio de cultivo M.S. suplementado con jugo de piña (MPi) es la más eficiente para inducir la germinación completa, con formación de tallo y hojas en las especies de estudio, observadas dentro de las 13 semanas de evaluación, siendo superado por una semana solo por el medio de M.S. suplementado con plátano, para la germinación en la especie Epidendrum secundum.

El medio de M. S. suplementado con agua de coco es la menos eficiente para el proceso de germinación en las especies en estudio, con la cual no se alcanzó a la formación de órganos vegetativos en las especies Bletia catenulata y Rodriguezia longifolia, siendo su comportamiento similar al medio M.S. sin suplemento.

Se estableció de manera artificial la división de la germinación en cinco etapas, que son: imbibición, cambio de coloración por la transformación de protoplastidios en cloroplastos, inicio de la división celular, formación del protocormo y diferenciación de los órganos vegetativos.

Autor corresponsal. Máximo. A Chacón - Campana.

americo.chacon@unsaac.edu.pe

\section{BIBLIOGRAFÍA}

Arditti, J. (1992). Fundamentals of Orchid Biology. Wiley-Interscience. New York. 
Ardiiti, J \& Ernest, R. (1993). Micropropagation of orchids. Wiley-Interscience Publication. New York. 682 p.

Gomes, A., Pascual, M., Villa, F. \& Carvalho, F. (2006). Agua de coco y pulpa de banana en cultivo in-vitro de plántulas de orquídea. Revista CERES, 53, 608-613.

Murashige, T. \& Skoog, F. (1962). A revised Medium for Rapid Growth and Bloassays with Tobacco Culture. Physiol Plantarum. 473-493.

Roca, W. \& Mroginsky, L. (1991). Cultivo de Tejidos Vegetales en la Agricultura. Fundamentos y Aplicaciones. Cap. 18. Parte B. CIAT, Colombia. 421-446 p.

Salazar, S. y Orlando, G. (2012). Evaluación del efecto de dos suplementos orgánicos en la germinación in vitro de orquídeas nativas de la Provincia de Pamplona, Colombia. Revista Colombiana Biotecnol,14(1), 53-59.

Salazar, S. \& Anaya, A. (2013). Evaluación de diferentes medios de cultivo in vitro en el desarrollo de híbridos de Phalaenopsis (Orchidaceae).Revista Colombiana de Biotecnología, 15(2). 97-105.

Sardi, L. \& Guzmán, S. (2007). Análisis de la variación de la tasa de germinación y crecimiento de las orquídeas Epidendrum secundum y Oncidium excavatum a través de medios de cultivo convencionales combinados con naturales. Tesis para optar el título de Biólogo. Universidad de Azuay. Cuenca. Ecuador. 